\title{
Myoglobin/Gold Nanoparticles/Carbon Spheres 3-D Architecture for the Fabrication of a Novel Biosensor
}

\author{
Xiao Chen, Jing Jing Zhang, Jie Xuan, and Jun Jie Zhu $(\bowtie)$ \\ Key Laboratory of Analytical Chemistry for Life Science, Ministry of Education, School of Chemistry and Chemical \\ Engineering, Nanjing University, Nanjing 210093, China \\ Received: 12 December 2008/Revised: 31 December 2008/Accepted: 1 January 2009 \\ (C) Tsinghua University Press and Springer-Verlag 2009. This article is published with open access at Springerlink.com
}

\begin{abstract}
A novel biosensor based on a myoglobin/gold nanoparticles/carbon spheres ( $\mathrm{Mb}-\mathrm{AuNPs}-\mathrm{CNs}$ ) 3-D architecture bioconjunction has been fabricated for the determination of hydrogen peroxide $\left(\mathrm{H}_{2} \mathrm{O}_{2}\right)$. Cyclic voltammetry (CV), Fourier transform infrared (FT-IR) spectroscopy and scanning electron microscopy (SEM) were used to characterize the bioconjunction of the AuNPs-CNs with Mb. Experimental results demonstrate that the AuNPs-CNs hybrid material is more effective in facilitating electron transfer of the immobilized enzyme than CNs alone, which can be attributed to the unique nanostructure and larger surface area of the bioconjunction. The biosensor displayed good performance for the detection of $\mathrm{H}_{2} \mathrm{O}_{2}$ with a wide linear range from $0.28 \mu \mathrm{mol} / \mathrm{L}$ to $116.5 \mu \mathrm{mol} / \mathrm{L}$ and a detection limit of $0.12 \mu \mathrm{mol} / \mathrm{L}$. The Michaelis-Menten constant $K_{\mathrm{M}}^{\text {app }}$ value was estimated to be $0.3 \mathrm{mmol} / \mathrm{L}$. The resulting biosensor exhibited fast amperometric response, and good stability, reproducibility, and selectivity to $\mathrm{H}_{2} \mathrm{O}_{2}$.
\end{abstract}

\section{KEYWORDS}

Biosensor; myoglobin; gold nanoparticles; carbon spheres; hydrogen peroxide; direct electron transfer

\section{Introduction}

The design of mediator-free third generation enzyme electrodes, which enable the detection of chemical/ biological molecules by a direct electron transfer between the enzyme and the conjoint electrode, is of considerable interest and importance. Extensive work has been carried out with redox protein films over the past few decades in order to find methods to increase the electron transfer rate between enzyme and electrode [1-8]. For example, a variety of carbonbased materials such as carbon nanotubes (CNTs) [9 $-11]$ and carbon nanofibers (CNFs) $[12,13]$ have been successfully employed for the direct electron transfer of proteins in films. Their properties of hydrophilicity, nontoxicity, excellent film-forming ability, and remarkable biocompatibility offer excellent prospects for biocompatible immobilization matrices and the design of novel biosensors. Carbon spheres (CNs), with similar electrochemical properties to CNTs, are spherical structures with a carbonized core and a hydrophilic surface. The complete surface of the carbon spheres can be activated by synthesis using aqueous glucose solutions [14]. Carbon spheres have a large functionalized surface available for loading with noble metal nanoparticles and binding with

Address correspondence to jjzhu@nju.edu.cn 
proteins due to the large number of functional groups furnished by the starting materials. Moreover, the cavities in carbon spheres may provide a protective microenvironment for the enzymes, facilitating retention of their stability and activity. In contrast, the use of CNTs in biosensors is limited by the fact that their closed shell does not allow for a high degree of functionalization $[9,15]$. Therefore, carbon spheres may be of more interest since they have potential advantages for many advanced applications. To our best knowledge, only a few studies of the use of carbon spheres in electrochemical immunoassay have been reported [16]. Such limited attention is not consistent with the remarkable properties and potential merits of carbon spheres.

Myoglobin ( $\mathrm{Mb})$ is a single-chain protein of 153 amino acids containing a heme (iron-containing porphyrin) group in the center which is found in mammalian skeleton and muscle tissues. $\mathrm{Mb}$ functions physiologically in the storage of oxygen and in the enhancement of the rate of oxygen diffusion, and has catalytic activity for $\mathrm{H}_{2} \mathrm{O}_{2}$ decomposition similar to horseradish peroxidase $[17,18]$. It is an ideal model molecule for the study of electron transfer reactions of heme proteins and also for biosensing and biocatalysis. However, the direct electron transfer between the redox center of the immobilized enzyme and an electrode is often shielded by the insulating outer protein shell [19]. Because of their controllable size and functional surface, carbon spheres act as meso-scale connectors to bind the enzyme and enhance the possibility of direct electron transfer between protein and electrode surface. Furthermore, a core-shell hybrid material fabricated by coating carbon spheres with citrate-stabilized gold nanoparticles (AuNPs) can optimize the use of carbon spheres in fabricating an immunosensor [16]. Therefore, exploitation of this hybrid material for construction of a Mb-based mediator free $\mathrm{H}_{2} \mathrm{O}_{2}$ biosensor is a promising area of research.

In the work described here, $\mathrm{Mb}$ was immobilized on such a hybrid material to form a myoglobin/ gold-nanoparticles/ carbon spheres ( $\mathrm{Mb}-\mathrm{AuNPs}^{-}$ CNs) 3-D architecture bioconjunction that can be assembled on a glassy carbon electrode (GCE) for the construction of a novel biosensor. Scanning electron microscopy (SEM) was used to monitor the fabrication process and FT-IR was employed to investigate the conformation. This proposed strategy for the preparation of the hybrid material is simple and effective. The direct electrochemistry and analytical performance of the resulting biosensor in the determination of hydrogen peroxide have been investigated.

\section{Experimental}

\subsection{Reagents}

Glucose (analytical purity) was purchased from Beijing Chemical Reagent Factory. Mb (from horse heart) was obtained from Sigma Chemical Co., and used as received. Chloroauric acid $\left(\mathrm{HAuCl}_{4} \cdot 4 \mathrm{H}_{2} \mathrm{O}\right)$, trichloroacetic acid (TCA), trisodium citrate, and hydrogen peroxide $\left(\mathrm{H}_{2} \mathrm{O}_{2}, 30 \%\right.$, w/v solution) were obtained from Shanghai Chemical Reagent Co. Poly(diallyldimethylammonium chloride) (PDDA, $20 \%, w / w$ in water, $M W=200,000-350,000)$ was from Sigma-Aldrich Chemical Co. Nafion, a $5 \mathrm{wt} \%$ solution in a mixture of lower aliphatic alcohols and $20 \%$ water, was obtained from Aldrich. All chemicals were of analytical grade and used without further purification.

The $0.1 \mathrm{~mol} / \mathrm{L}$ phosphate buffer solutions (PBS) with different $\mathrm{pH}$ values were prepared by mixing stock standard solutions of $\mathrm{Na}_{2} \mathrm{HPO}_{4}$ and $\mathrm{NaH}_{2} \mathrm{PO}_{4}$ and adjusting the $\mathrm{pH}$ with $0.1 \mathrm{~mol} / \mathrm{L} \mathrm{H}_{3} \mathrm{PO}_{4}$ or $\mathrm{NaOH}$. A $0.20 \%$ PDDA solution was prepared by diluting 20\% PDDA with $20 \mathrm{mmol} / \mathrm{L}$ Tris and 20 $\mathrm{mmol} / \mathrm{L} \mathrm{NaCl}$ solution. A $0.5 \%$ Nafion solution was prepared by diluting the $5 \%$ Nafion solution with ethanol. Electrochemical impedance spectroscopy (EIS) experiments were performed in $0.1 \mathrm{~mol} / \mathrm{L}$ $\mathrm{KCl}$ solution containing $10.0 \mathrm{mmol} / \mathrm{L} \mathrm{Fe}(\mathrm{CN})_{6}{ }^{3-} /$ $\mathrm{Fe}(\mathrm{CN})_{6}{ }^{4-}(1: 1)$. All aqueous solutions were prepared with distilled water.

\subsection{Apparatus and measurements}

Scanning electron micrographs (SEM) were obtained with a Hitachi S4800 scanning electron microscope. Fourier transform infrared (FT-IR) spectra were 
recorded on a Vector 22 FT-IR spectrometer (Bruker). Static water contact angles were measured at $25^{\circ} \mathrm{C}$ by a contact angle goniometer (Rame-Hart-100) employing drops of pure water. The readings were stabilized and taken within $120 \mathrm{~s}$ after addition. Powder X-ray diffraction (XRD) data were collected on a Shimadzu XD-3A X-ray diffractometer (Cu K $\alpha$ radiation, $\lambda=0.15418 \mathrm{~nm}$ ).

Electrochemical measurements were performed on a CHI 630 electrochemical workstation (Chenhua, Shanghai, China) with a conventional threeelectrode system comprising a platinum wire as the auxiliary electrode, a saturated calomel electrode (SCE) as the reference and a modified GCE as the working electrode. EIS analyses were performed with an Autolab PGSTAT12 (Eco Chemie BV, The Netherlands) and controlled by GPES 4.9 and FRA 4.9 software with a three-electrode system.

\subsection{Preparation of $\mathrm{Mb}-\mathrm{AuNPs}-\mathrm{CNs}$ bioconjuction}

The hybrid material AuNPs-CNs were synthesized according to Ref. [16]. CNs were synthesized in aqueous glucose solutions via a microwavehydrothermal route. The $\mathrm{CNs}$ were then dispersed in PDDA solution and stirred for $20 \mathrm{~min}$. After centrifugation and rinsing three times in distilled water, the resulting $\mathrm{CNs}$ were then dispersed in a $\mathrm{Au}$ colloid solution and stirred for another $20 \mathrm{~min}$.

AuNPs-CNs hybrids (15 mg) or CNs were dispersed in a solution of $\mathrm{Mb}(2 \mathrm{mg} / \mathrm{mL})$ and stirred for $24 \mathrm{~h}$ to allow protein adsorption. The resulting materials were then centrifuged and washed three times with $0.1 \mathrm{~mol} / \mathrm{L}$ PBS ( $\mathrm{pH}$ 6.0). By calculating the difference in the concentration of the protein before and after adsorption, we found that about $268 \mu \mathrm{g}$ of $\mathrm{Mb}$ was immobilized onto each mg of AuNPs-CNs hybrid in the the fabrication of the $\mathrm{Mb}-\mathrm{AuNPs}-\mathrm{CNs}$ 3-D architecture bioconjunction.

\subsection{Preparation of biosensors based on $\mathbf{M b}$ AuNPs-CNs and $\mathrm{Mb}-\mathrm{CNs}$}

A GCE with a diameter of $3 \mathrm{~mm}$ was first polished to a mirror surface with a $0.05 \mu \mathrm{m} \alpha-\mathrm{Al}_{2} \mathrm{O}_{3}$ slurry, and then successively ultrasonicated in distilled water and ethanol. The cleaned electrode was dried with a stream of nitrogen immediately before use. $19.1 \mathrm{mg}$
$\mathrm{Mb}-\mathrm{AuNPs}-\mathrm{CNs}$ bioconjunction or $\mathrm{Mb}-\mathrm{CNs}$ hybrid material was redispersed in $1 \mathrm{~mL}$ of $0.1 \mathrm{~mol} / \mathrm{L}$ PBS ( $\mathrm{pH}$ 6.0), and $5 \mu \mathrm{L}$ of these suspensions were deposited on the surface of a pretreated GCE. They were then left to dry at $4{ }^{\circ} \mathrm{C} .0 .5 \%$ Nafion solution was then added for encapsulation. The electrodes were stored for $24 \mathrm{~h}$ at $4{ }^{\circ} \mathrm{C}$ when not in use.

\section{Results and discussion}

\subsection{Characterization of the Mb-AuNPs-CNs hybrids}

In order to confirm the assembly of AuNPs on the $\mathrm{CNs}$, the materials were investigated by SEM. Figure 1(a) shows that CNs with an average diameter of 250 $\mathrm{nm}$ were uniform in size and morphology. Making a comparison between Figs. 1(a) and 1(b), the distinctive difference in morphology before and after loading with AuNPs can be observed. The numerous individual light nanodots shown in Fig. 1(b) are well-dispersed AuNPs which decorate the $\mathrm{CNs}$ surface quite uniformly.

Figure 1(c) shows the energy-dispersive (EDS) analysis of the AuNPs-CNs hybrids. The atomic percentages of carbon and gold are $73.4 \%$ and $4.0 \%$, respectively. What is also worth noting is that the atomic percentage of oxygen is $18.1 \%$, suggesting the presence of oxygen-containing functional groups from the starting materials.

Figure 1(d) shows the X-ray diffraction pattern of the AuNPs-CNs hybrids. All the diffraction peaks can be indexed to a typical face-centered cubic (fcc) lattice, in good agreement with the standard pattern for metallic Au. The diffraction peaks at $2 \theta=38.3^{\circ}$, $43.5^{\circ}, 65.0^{\circ}$, and $77.7^{\circ}$ can be assigned to the (111), (200), (220), and (311) reflections of Au.

Contact angle measurements were carried out in order to investigate changes in the properties of the carbon sphere surfaces after immobilization of AuNPs. As shown in Figs. 1(e) and 1(f), the CNs and AuNPs-CNs gave contact angles of $47.5^{\circ}$ and $33^{\circ}$, respectively. The hybrid material shows a lower contact angle, indicating a better hydrophilic surface for enzyme adhesion, which should improve the biocompatibility of the electrode surface and facilitate retention of enzyme activity.

$\mathrm{Mb}$ entrapped in the composite film was 


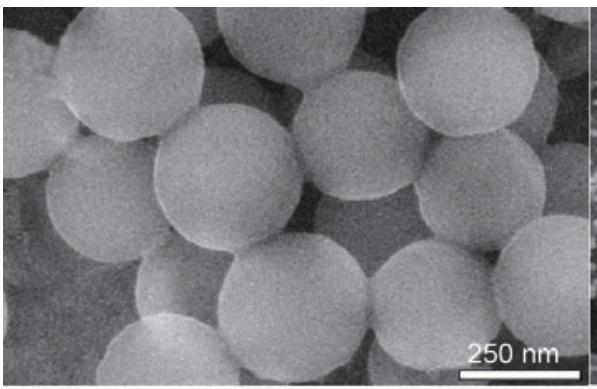

(a)

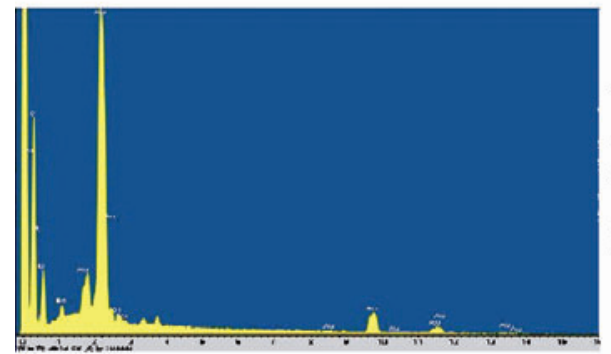

(c)

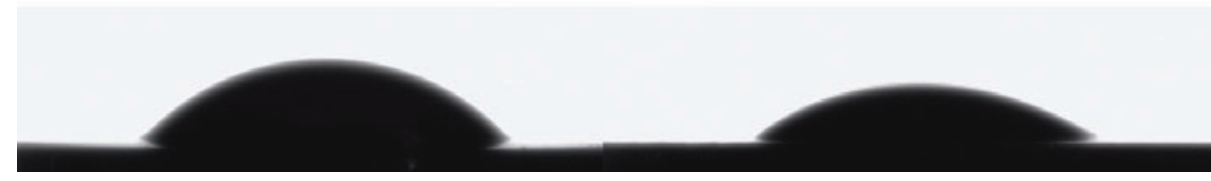

(e)

Figure 1 SEM images of (a) CNs and (b) AuNPs-CNs hybrids; (c) EDS image of AuNP-CNs hybrid material; (d) XRD pattern of AuNP-CNs hybrid material; Contact angles of GCE modified with (e) CNs and (f) AuNPs-CNs hybrids

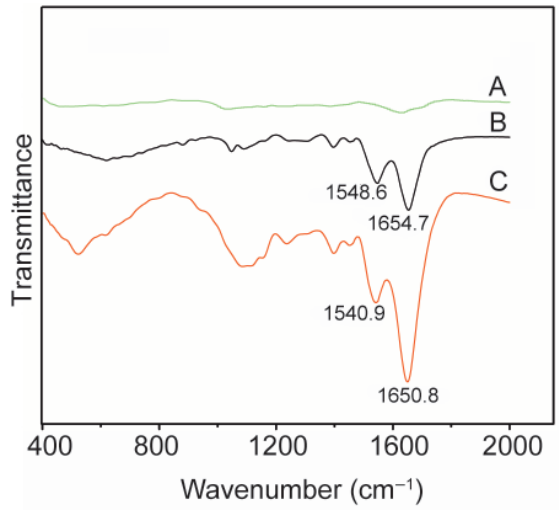

(a)

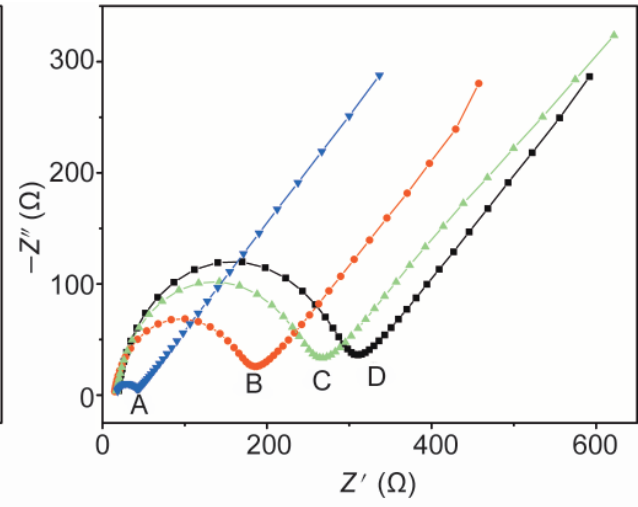

(b)
Figure 2 (a) FT-IR spectra of (A) AuNPs-CNs, (B) Mb, and (C) Mb-AuNPs-CNs films; (b) electrochemical impedance spectroscopy for (A) bare GCE, (B) AuNPs-CNs, (C) Mb-AuNPs-CNs, and (D) $\mathrm{CNs} / \mathrm{GCE}$ recorded in $0.1 \mathrm{~mol} / \mathrm{L} \mathrm{KCl}$ solution containing $10.0 \mathrm{mmol} / \mathrm{L} \mathrm{Fe}(\mathrm{CN})_{6}{ }^{{ }^{-}} / \mathrm{Fe}(\mathrm{CN})_{6}{ }^{{ }^{-}}(1: 1)$ chains. The amide I band (in the range $1700-1600 \mathrm{~cm}^{-1}$ ) is ascribed to $\mathrm{C}=\mathrm{O}$ stretching vibrations of peptide linkages in the protein backbone. The amide II band (in the range $\left.1600-1500 \mathrm{~cm}^{-1}\right)$ is attributed to a combination of $\mathrm{N}-\mathrm{H}$ in plane bending and $\mathrm{C}$ $\mathrm{N}$ stretching of the peptide groups. The spectrum of the AuNPs-CNs precursor (curve A in Fig. 2(a)) shows no obvious spectral features. As shown in plot $C$ in Fig. 2(a), the positions of the amides I $\left(1650.8 \mathrm{~cm}^{-1}\right)$ and II $\left(1540.9 \mathrm{~cm}^{-1}\right)$ bands of $\mathrm{Mb}$ in the $\mathrm{Mb}-$ AuNPs-CNs hybrid were nearly the same as those (amide I, $1654.7 \mathrm{~cm}^{-1}$; amide II, $1548.6 \mathrm{~cm}^{-1}$ ) of native $\mathrm{Mb}$ (curve B in Fig. 2(a)). This indicates that the essential features of the native $\mathrm{Mb}$ secondary structure were mostly retained in $\mathrm{Mb}-$ AuNPs-CNs, implying that the porous structure of the hybrid offers a protective microenvironment allowing $\mathrm{Mb}$ to retain its enzymatic stability and activity. The slight shifts of amide I bands (from 1654.7 to $1650.8 \mathrm{~cm}^{-1}$ ) and amide II bands (from 1540.9 to $1548.6 \mathrm{~cm}^{-1}$ ) suggest some interaction between $\mathrm{Mb}$ and the AuNPs-CNs hybrid. The AuNPs-CNs film may provide a promising matrix investigated by FT-IR spectroscopy, which is an effective method to probe the secondary structure of proteins. The characteristic amide I and amide II bands of proteins provide detailed information about the secondary structure of the polypeptide for $\mathrm{Mb}$ immobilization and biosensor fabrication due to its satisfactory biocompatibility.

The fabrication process was also monitored by EIS. The redox couple $\mathrm{Fe}(\mathrm{CN})_{6}{ }^{3-} / \mathrm{Fe}(\mathrm{CN})_{6}{ }^{4-}$ is widely used as an electrochemical probe in electrochemical 
impedance studies, especially for the characterization of biomaterial-modified electrodes. Figure 2(b) shows Nyquist plots for bare GCE, AuNPs-CNs/GCE, $\mathrm{Mb}-\mathrm{AuNPs}-\mathrm{CNs} / \mathrm{GCE}$, and CNs/GCE. At a bare $\mathrm{GCE}$, the redox process of the $\mathrm{Fe}(\mathrm{CN})_{6}{ }^{3-} / \mathrm{Fe}(\mathrm{CN})_{6}{ }^{4-}$ probe showed an electron transfer resistance of about $17 \Omega$ (curve A in Fig. 2(b)). When the GCE was modified by carbon spheres (curve D in Fig. 2(b)), the diameter of the semicircle increased to $309 \Omega$. The AuNPs-CNs hybrid (curve B in Fig. 2(b)) showed far less resistance with the semicircle diameter being $177 \Omega$, suggesting the hybrid has an excellent electrical conductivity. When $\mathrm{Mb}$ was immobilized on the AuNPs-CNs hybrid (curve C in Fig. 2(b)), the electron transfer resistance was slightly increased to $259 \Omega$. Owing to the dielectric behavior of enzyme molecules for interfacial electron transfer processes, the higher enzyme coverage will result in a higher barrier for interfacial electron transfer. These data confirm that $\mathrm{Mb}$ had been successfully immobilized on the AuNPs-CNs hybrid and blocked the electron exchange between the redox probe and the electrode.

\subsection{Direct electron transfer of the biosensor}

Figure 3(a) shows typical cyclic voltammograms (CVs) for CNs/GCE, Mb-CNs/GCE, AuNPs-CNs/ $\mathrm{GCE}$, and $\mathrm{Mb}-\mathrm{AuNPs}-\mathrm{CNs} / \mathrm{GCE}$ at a scan rate of $0.2 \mathrm{~V} / \mathrm{s}$. No obvious redox peaks were observed at the CNs/GCE (curve A) and AuNPs-CNs / GCE (curve $\mathrm{C}$ ), which suggests that neither $\mathrm{CNs}$ nor AuNPs-CNs were electroactive in the potential range studied. The $\mathrm{CV}$ of $\mathrm{Mb}-\mathrm{CNs} / \mathrm{GCE}$ (curve $\mathrm{B}$ ) had a pair of quasi-reversible redox peaks, implying direct electron transfer between the immobilized $\mathrm{Mb}$ and the electrode. In comparison, the redox peaks observed on the $\mathrm{Mb}-\mathrm{AuNPs}-\mathrm{CNs} / \mathrm{GCE}$ (curve D) were remarkably large. The cathodic and anodic peak potentials were $-0.399 \mathrm{~V}$ and $-0.338 \mathrm{~V}$, respectively. The formal potential $\left(E_{\mathrm{p}}\right)$, calculated from the average value of cathodic and anodic peak potentials, was $-0.369 \mathrm{~V}$, which is characteristic of the reversible electrode process of the heme Fe(III)/ Fe(II) redox couple in immobilized $\mathrm{Mb}$. The potential difference between cathodic and anodic peak potentials of $61 \mathrm{mV}$ at this scan rate implies a high speed of the electron transfer process for the electroactive center of the immobilized $\mathrm{Mb}$. Therefore, it can be concluded that direct electron transfer between the $\mathrm{Mb}$ and electrode is greatly enhanced by the presence of the AuNPs-CNs hybrids which provide a biocompatible microenvironment for the entrapped $\mathrm{Mb}$.

Figure 3(b) displays the $\mathrm{CVs}$ of $\mathrm{Mb}-\mathrm{AuNPs}-\mathrm{CNs} /$ GCE with varying scan rates from 0.05 to $0.5 \mathrm{~V} / \mathrm{s}$. The cathodic and anodic peak currents of $\mathrm{Mb}$ both increased with increasing scan rates, and the cathodic and anodic peak potentials showed a slight shift and the peak to peak separation also increased. As shown in the inset of Fig. 3(b), both the cathodic and anodic peak currents increased linearly with scan rates from 0.05 to $0.5 \mathrm{~V} / \mathrm{s}$. This indicates that the electron transfer between $\mathrm{Mb}$ and GCE is not difficult and that it is a surface-controlled electrochemical process. According to the Laviron method for a surfacecontrolled electrochemical system [20], the apparent heterogeneous electron transfer rate constant $\left(k_{\mathrm{s}}\right)$ of $\mathrm{Mb}$ immobilized on $\mathrm{Mb}-\mathrm{AuNPs}-\mathrm{CNs} / \mathrm{GCE}$ was estimated to be about $6.7 \mathrm{~s}^{-1}$. This value of $k_{\mathrm{s}}$ is higher than those reported for systems involving $\mathrm{Mb}$ or hemoglobin $(\mathrm{Hb})$ immobilized on various inorganic hybrid films without metal nanoparticles, such as a $\mathrm{Mb} /$ multi-walled carbon nanotube film $\left(5.4 \mathrm{~s}^{-1}\right)$ or an $\mathrm{Hb}-\mathrm{Nafion}-\mathrm{CNF} / \mathrm{GCE}\left(2.4 \mathrm{~s}^{-1}\right)$ [3, 13], suggesting that the presence of the AuNPs enhanced the electron transfer rate of $\mathrm{Mb}$ immobilized on the AuNPs-CNs hybrid. According to Faraday's law, $Q=n F A \Gamma^{*}$, where $F$ is Faraday constant. The charge $Q$ can be obtained by integrating the reduction peak of $\mathrm{Mb}$, and $n$ and $A$ stand for the number of electrons transferred and the geometrical surface area of the electrode (3 $\mathrm{mm}$ diameter), respectively. From this equation, the surface concentration of electroactive $\mathrm{Mb}\left(\Gamma^{*}\right)$ at $\mathrm{Mb}$ -AuNPs-CNs/GCE was estimated to be $1.61 \times 10^{-10}$ $\mathrm{mol} / \mathrm{cm}^{2}$. This value is an order of magnitude higher than that of the theoretical monolayer coverage $\left(1.58 \times 10^{-11} \mathrm{~mol} / \mathrm{cm}^{2}\right)$ estimated on the basis of the crystallographic dimensions of $3.0 \mathrm{~nm} \times 3.5 \mathrm{~nm} \times 2.3$ $\mathrm{nm}$ for $\mathrm{Mb}$ [21], assuming each molecule has its long axis parallel to the electrode surface. This suggests that the matrix may trap multiple layers of $\mathrm{Mb}$ and greatly facilitate approach of its active site to the electrode. 


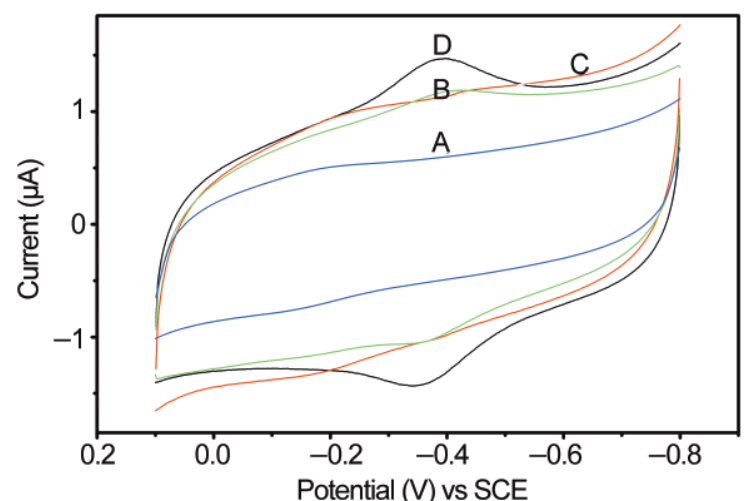

(a)

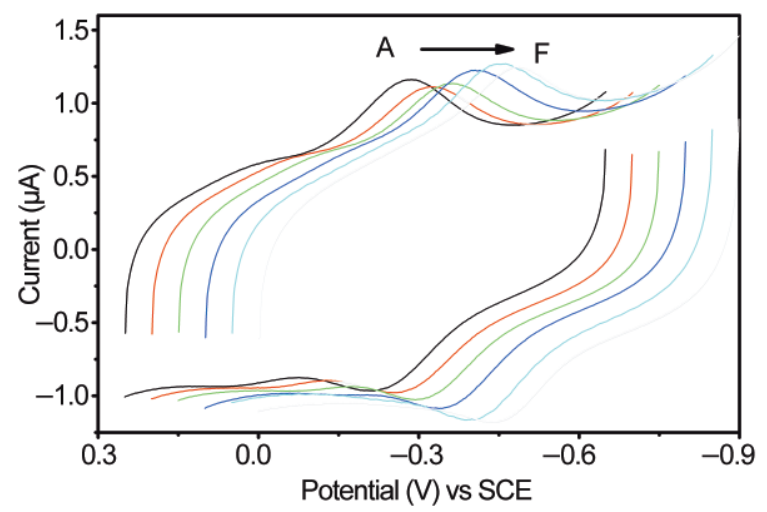

(c)

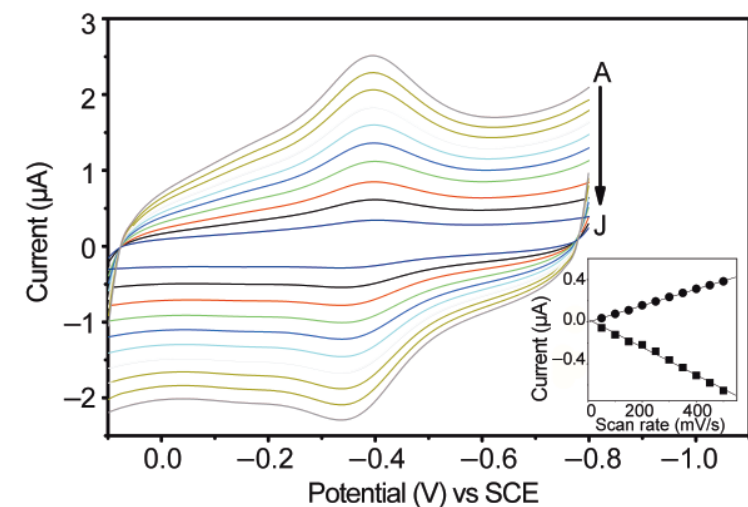

(b)

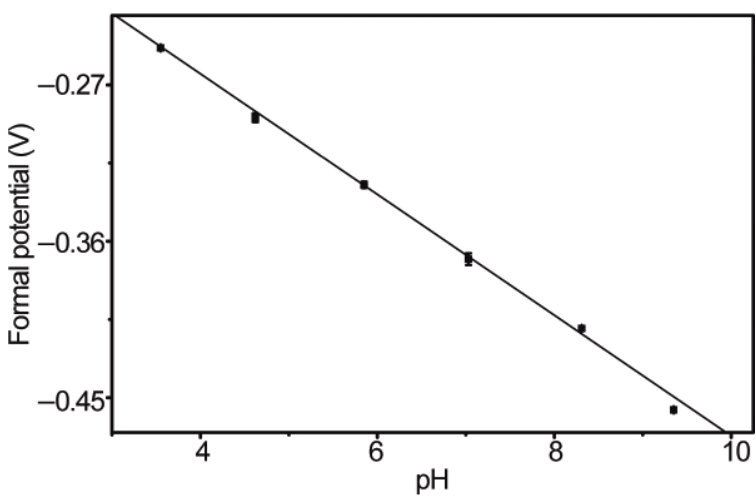

(d)

Figure 3 (a) Cyclic voltammograms of (A) CNs/GCE, (B) Mb-CNs/GCE, (C) AuNPs-CNs/GCE, and (D) Mb-AuNPs-CNs/GCE in $0.1 \mathrm{~mol} / \mathrm{L} \mathrm{pH}$ 7.0 PBS at a scan rate of $0.2 \mathrm{~V} / \mathrm{s}$; (b) cyclic voltammograms of Mb-AuNPs-CNs/GCE in $0.1 \mathrm{~mol} / \mathrm{L} \mathrm{PBS} \mathrm{(pH} \mathrm{7.0)} \mathrm{with} \mathrm{different} \mathrm{scan} \mathrm{rates} \mathrm{(V/s):}$ (A) 0.5, (B) 0.45, (C) 0.4, (D) 0.35, (E) 0.3, (F) 0.25, (G) 0.2, (H) 0.15, (I) 0.1, (J) 0.05, and (Inset) plot of peak currents vs. scan rates; (C) cyclic voltammograms of Mb-AuNPs-CNs/GCE in $0.1 \mathrm{~mol} / \mathrm{L} \mathrm{PBS} \mathrm{(pH} \mathrm{7.0)} \mathrm{with} \mathrm{different} \mathrm{pH:} \mathrm{(A)} \mathrm{3.55,} \mathrm{(B)} \mathrm{4.62,} \mathrm{(C)} \mathrm{5.85,} \mathrm{(D)} \mathrm{7.03,} \mathrm{(E)} \mathrm{8.31,} \mathrm{(F)} \mathrm{9.35} \mathrm{at} \mathrm{a}$ scan rate of $0.2 \mathrm{~V} / \mathrm{s}$; (d) plot of formal potential vs $\mathrm{pH}$ in $0.1 \mathrm{~mol} / \mathrm{L} \mathrm{PBS}$ at a scan rate of $0.2 \mathrm{~V} / \mathrm{s}$

The dependence of the electrochemical behavior of $\mathrm{Mb}-\mathrm{AuNPs}-\mathrm{CNs} / \mathrm{GCE}$ on the $\mathrm{pH}$ was studied. As shown in Fig. 3(c), the potentials of both reduction and oxidation peaks shifted with the increase of solution $\mathrm{pH}$ from 3.55 to 9.35 . The $\mathrm{pH}$ increase led to a linear negative shift in peak potential (Fig. 3(d)). It is well known that a $\mathrm{pH}$ increase can decrease the formal potentials of heme proteins that undergo proton-coupled electron transfer [22]. This redox Bohr effect, a shift in the formal potential as a function of $\mathrm{pH}$, results from the change in the protonation of a water molecule at the sixth coordination position in the heme iron and also protonation of the protolytic groups around the heme with changing $\mathrm{pH}$ [23]. The shift in peak potentials for $\mathrm{Mb}^{-\mathrm{AuNP}}-\mathrm{CNs} / \mathrm{GCE}$ with $\mathrm{pH}$ therefore indicates that the redox reaction is accompanied by the transfer of protons. The value of the slope $(35 \mathrm{mV} / \mathrm{pH})$ was smaller than the theoretically expected value, $59 \mathrm{mV} / \mathrm{pH}$, for a one-electron one-proton reaction [24]. This may be attributed to the influence of the protonation states of the ligands coordinated to the heme iron and the amino acids around the heme, or to the protonation of the water molecule coordinated to the central iron [25].

\subsection{Electrocatalytic activity of the biosensor}

The determination of $\mathrm{H}_{2} \mathrm{O}_{2}$ is of great importance in many fields, such as clinical, food, pharmaceutical, and environmental analyses. Figures 4(a) and 4(c) show the bioelectrocatalytic activity of $\mathrm{Mb}$ -AuNPs-CNs/GCE and $\mathrm{Mb}-\mathrm{CNs} / \mathrm{GCE}$ for $\mathrm{H}_{2} \mathrm{O}_{2}$. In the presence of $\mathrm{H}_{2} \mathrm{O}_{2}$, an obvious increase in the cathodic peak current at around $-0.36 \mathrm{~V}$ was observed, together with a decrease of anodic peak current. This demonstrates that the electrocatalytic 
reduction processes in $\mathrm{Mb}-\mathrm{AuNPs}-\mathrm{CNs} / \mathrm{GCE}$ and $\mathrm{Mb}-\mathrm{CNs} / \mathrm{GCE}$ are typical of $\mathrm{Mb}$. A possible mechanism for electrocatalytic reduction of $\mathrm{H}_{2} \mathrm{O}_{2}$ at an $\mathrm{Mb}$-based enzyme electrode has been reported [26], which can be expressed as follows:

$$
\begin{aligned}
& \mathrm{MbFe}+\mathrm{H}_{2} \mathrm{O}_{2} \rightarrow \text { Compound } \mathrm{I}+\mathrm{H}_{2} \mathrm{O} \\
& \text { Compound I }+\mathrm{e}^{-}+\mathrm{H}^{+} \rightarrow \text { Compound II } \\
& \text { Compound } \mathrm{II}+\mathrm{e}^{-}+\mathrm{H}^{+} \rightarrow \mathrm{MbFe}+\mathrm{H}_{2} \mathrm{O}
\end{aligned}
$$

A significantly stronger peak current was observed for the $\mathrm{CV}$ curve for $\mathrm{Mb}-\mathrm{AuNPs}-\mathrm{CNs}$ compared to that for $\mathrm{Mb}-\mathrm{CNs} / \mathrm{GCE}$ as shown in Fig. 4(d). Such enhanced Faradic responses are of great importance in voltammetric investigations of interfacial electron transfer in redox proteins, and are also highly desired for development of new biosensors. The observed currents for the $\mathrm{Mb}$ -AuNPs-CNs/GCE and Mb-CNs/GCE electrodes both showed a good linear relationship with the concentration of $\mathrm{H}_{2} \mathrm{O}_{2}$ in the range $0.28-116.5$ $\mu \mathrm{mol} / \mathrm{L}$ and $14.2-72.5 \mu \mathrm{mol} / \mathrm{L}$, respectively. The linear regression equations for $\mathrm{Mb}-\mathrm{AuNPs}-\mathrm{CNs} /$ GCE and $\mathrm{Mb}-\mathrm{CNs} / \mathrm{GCE}$ were $I=0.1189+0.03788 \mathrm{C}$ $(R=0.999, n=18)$ and $I=0.4704+0.02528 C(R=0.995$, $n=8)$ respectively. From the slope of $0.03788 \mu \mathrm{A} /$ $(\mu \mathrm{mol} / \mathrm{L})$, the limit of detection for $\mathrm{Mb}-\mathrm{AuNPs}-$ CNs/GCE was estimated to be $0.12 \mu \mathrm{mol} / \mathrm{L}$ at a signal-to-noise ratio of $3 \sigma . \mathrm{Mb}-\mathrm{AuNPs}^{-\mathrm{CNs} / \mathrm{GCE}}$ showed a significantly better electrocatalytic response to $\mathrm{H}_{2} \mathrm{O}_{2}$ than $\mathrm{Mb}-\mathrm{CNs} / \mathrm{GCE}$, which can possibly be attributed to the unique electronic properties of AuNPs on account of their quantum size confinement and biocompatability.

When the concentration of $\mathrm{H}_{2} \mathrm{O}_{2}$ was higher than $116.5 \mu \mathrm{mol} / \mathrm{L}$, a response plateau was observed, showing the characteristics of the Michaelis-

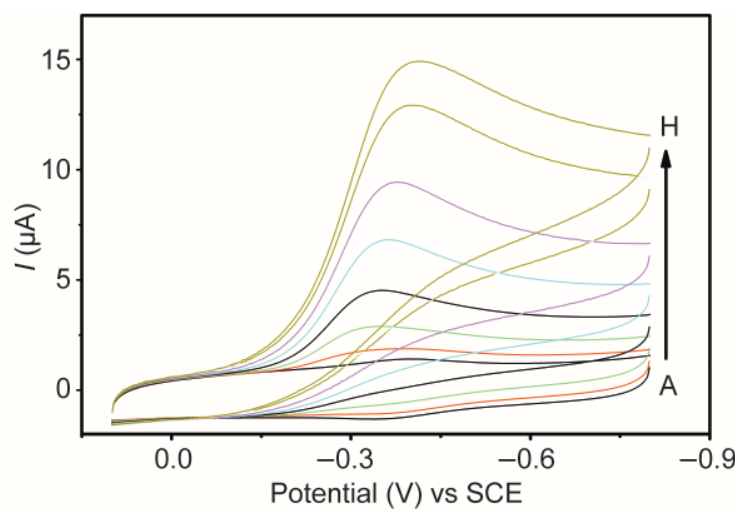

(a)

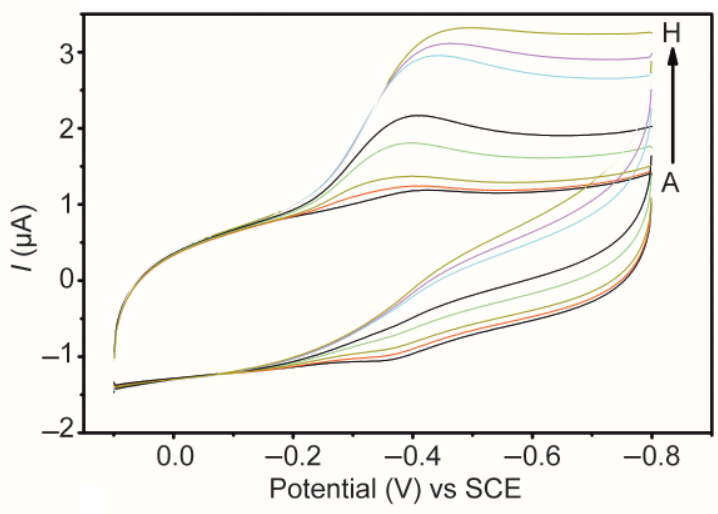

(c)

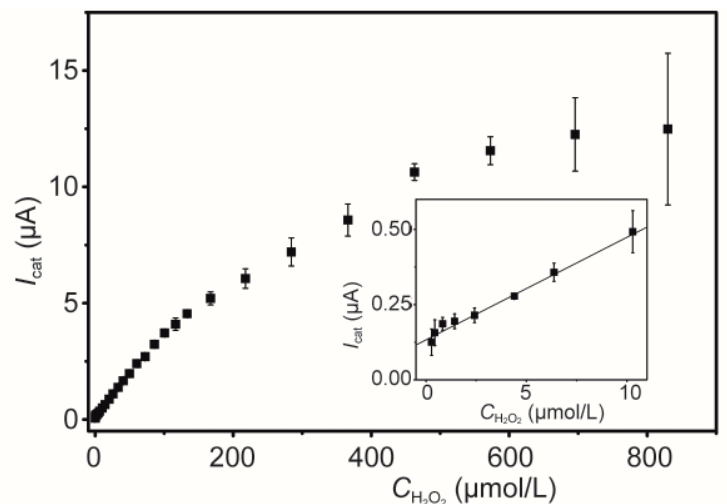

(b)

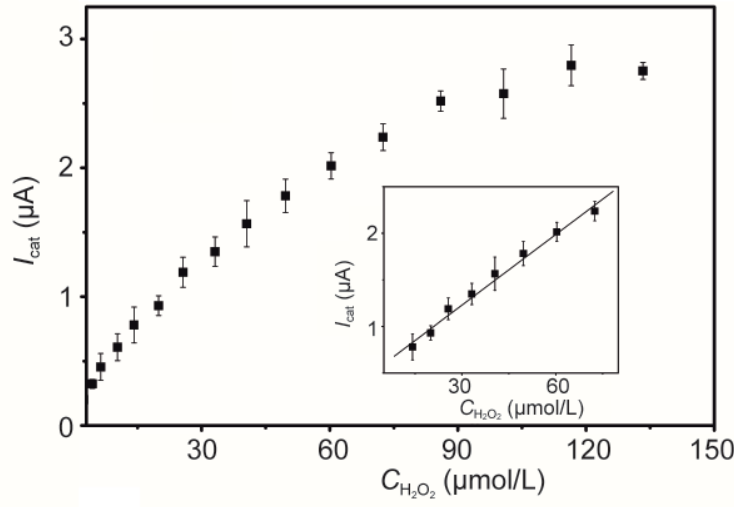

(d)

Figure 4 (a) Cyclic voltammograms of Mb-AuNPs-CNs/GCE in $0.1 \mathrm{~mol} / \mathrm{L}$ PBS ( $\mathrm{pH}$ 7.0) with $\mathrm{H}_{2} \mathrm{O}_{2}$ concentrations ( $\mu \mathrm{mol} / \mathrm{L}$ ) of (A) 0, (B) 14.2, (C) 40.6, (D) 86.0, (E) 167.3, (F) 284.3, (G) 462.7, and (H) 572.8 (scan rate, $0.2 \mathrm{~V} / \mathrm{s}$ ); (b) plots of electrocatalytic current $\left(\mathrm{I}_{\text {cat }}\right.$ ) vs $\mathrm{H}_{2} \mathrm{O}_{2}$ concentration for Mb-AuNPs-CN/GCE and (Inset) linear plots of $I_{\text {cat }} \mathrm{vs}_{2} \mathrm{O}_{2}$ concentration; (c) cyclic voltammograms of Mb-CNs/GCE in $0.1 \mathrm{~mol} /$ L PBS (pH 7.0) with $\mathrm{H}_{2} \mathrm{O}_{2}$ concentrations ( $\mu \mathrm{mol} / \mathrm{L}$ ) of (A) 0, (B) 0.04, (C) 0.836, (D) 10.3, (E) 20.0, (F) 40.6, (G) 49.6, and (H) 60.3 (scan rate, $0.2 \mathrm{~V} / \mathrm{s}$ ); (d) plots of electrocatalytic current $\left(I_{\text {cat }}\right)$ vs $\mathrm{H}_{2} \mathrm{O}_{2}$ concentration for Mb-CNs/GCE and (Inset) linear plots of $I_{\text {cat }} v \mathrm{H}_{2} \mathrm{O}_{2}$ concentration 
Menten kinetic mechanism. The apparent MichaelisMenten constant $\left(K_{\mathrm{M}}^{\text {app }}\right)$, which gives an indication of the enzyme-substrate kinetics, can be obtained from the electrochemical version of the Lineweaver-Burk equation [27]:

$$
\frac{1}{I_{\mathrm{ss}}}=\frac{1}{I_{\max }}+\frac{K_{\mathrm{M}}^{\mathrm{app}}}{I_{\max } \mathrm{C}}
$$

where $I_{\mathrm{ss}}$ is the steady-state current after the addition of substrate, which can be obtained from CV, $I_{\max }$ is the maximum current under saturated substrate conditions and $C$ is the bulk concentration of the substrate. The value of the apparent MichaelisMenten constant $\left(K_{\mathrm{M}}{ }^{\text {app }}\right)$ can be determined by the slope $\left(K_{\mathrm{M}}{ }^{\text {app }} / I_{\max }\right)$ and the intercept $\left(1 / I_{\max }\right)$ for the plot of the reciprocal of the steady-state current $\left(I_{\mathrm{ss}}\right)$ versus the reciprocal of $\mathrm{H}_{2} \mathrm{O}_{2}$ concentration (C). This plot had a good linear relationship, since the linear regression equation was $1 / I_{\mathrm{ss}}=0.0694+20.8 / C(R=0.999, n=19)$. Accordingly, the $K_{\mathrm{M}}{ }^{\text {app }}$ value for the $\mathrm{Mb}-\mathrm{AuNPs}^{-}$ CNs/GCE was estimated to be $0.30 \mathrm{mmol} / \mathrm{L}$. This value is smaller than the reported values of 0.68 $\mathrm{mmol} / \mathrm{L}$ for $\mathrm{Hb}-\mathrm{CNT}$ powder microelectrodes [28] and $1.22 \mathrm{mmol} / \mathrm{L}$ for clay-Mb-AuCS-GCE [29], implying that our modified electrode exhibited a higher affinity for $\mathrm{H}_{2} \mathrm{O}_{2}$.

It was also found that $\mathrm{Mb}-\mathrm{AuNPs}-\mathrm{CNs} / \mathrm{GCE}$ showed bioelectrocatalytic activity for TCA. The detection of TCA is of great importance in pollution control, since it is a common organohalide environmental pollutant. In the presence of TCA a significant increase in the cathodic peak current at around $-0.36 \mathrm{~V}$ was observed, which suggested that the biosensor also has potential use in detecting such organohalide pollutants in the environment.

\subsection{Reproducibility and stability of the hydrogen peroxide biosensor}

To evaluate the electrode-to-electrode reproducibility, six $\mathrm{Mb}-\mathrm{AuNPs}-\mathrm{CNs}$ /GCEs were prepared independently under the same conditions. The relative standard deviation (R.S.D.) of the prepared biosensors was $4.4 \%$. The R.S.D. for six successive determinations at an $\mathrm{H}_{2} \mathrm{O}_{2}$ concentration of $4 \mu \mathrm{mol} / \mathrm{L}$ was $1.9 \%$. These results are better than the corresponding values for $\mathrm{Mb}$ in a $\mathrm{ZrO}_{2}$-grafted collagen hybrid [30], which were $5.5 \%$ for electrode-electrode reproducibility and $3.2 \%$ for successive determinations on one electrode, indicating the excellent reproducibility of $\mathrm{Mb}^{-}$ AuNPs-CNs/GCE.

The storage stability of the Mb-AuNPs-CNs / GCE was also studied. When not in use, the electrode was kept at $4{ }^{\circ} \mathrm{C}$ in a refrigerator. The response to $40 \mu \mathrm{mol} / \mathrm{L} \mathrm{H}_{2} \mathrm{O}_{2}$ retained $93.6 \%$ of its initial current after 30 days storage. This good long-term stability can be attributed to the good biocompatibility of the composite, which can provide a favorable microenvironment for retention of the bioactivity of $\mathrm{Mb}$.

\subsection{Selectivity of the hydrogen peroxide biosensor}

The selectivity of the new $\mathrm{H}_{2} \mathrm{O}_{2}$ biosensor was evaluated by studying the effect of adding substances that might interfere with the determination of $\mathrm{H}_{2} \mathrm{O}_{2}$. The results are shown in Table 1 . When concentrations of glucose, glycine, ascorbic acid, citric acid, ethanol, and acetic acid coexisting in the sample were twice that of $\mathrm{H}_{2} \mathrm{O}_{2}$, no significant interference was observed, indicating that these species did not affect the determination of $\mathrm{H}_{2} \mathrm{O}_{2}$. The high selectivity of the $\mathrm{Mb}-\mathrm{AuNPs}-\mathrm{CNs} / \mathrm{GCE}$ biosensor verified its applicability for real sample analysis.

\section{Conclusions}

In this work, carbon spheres were combined with gold nanoparticles and $\mathrm{Mb}$ to form a myoglobin/ gold nanoparticles/carbon spheres (Mb-AuNPsCNs) 3-D architecture bioconjunction, which can be used to construct a mediator-free $\mathrm{H}_{2} \mathrm{O}_{2}$ biosensor. The biosensor was more effective in facilitating the electron transfer of immobilized enzyme than using $\mathrm{CNs}$ alone, which can be attributed to the unique nanostructure and large surface area of the bioconjunction. The biosensor displayed broader linear range and lower detection limit for $\mathrm{H}_{2} \mathrm{O}_{2}$ determination, as compared to CNs-based $\mathrm{H}_{2} \mathrm{O}_{2}$ biosensors. Furthermore, the good long-term stability and reproducibility of this biosensor demonstrate its applicability for practical biomedical detection and environmental analysis. 
Table 1 Interference of various substrates $(20 \mu \mathrm{mol} / \mathrm{L})$ on the response of the $\mathrm{Mb}-$ AuNPs-CNs/GCE to $10 \mu \mathrm{mol} / \mathrm{L} \mathrm{H}_{2} \mathrm{O}_{2}$ in $0.1 \mathrm{~mol} / \mathrm{L} \mathrm{PBS}(\mathrm{pH}=7.0)$

\begin{tabular}{ccc}
\hline Substrate & Current ratio & Relative standard deviation $(n=6)(\%)$ \\
\hline Glucose & $1.03 \pm 0.12$ & 4.7 \\
Hlycine & $1.02 \pm 0.13$ & 5.4 \\
Ascorbic acid & $0.93 \pm 0.096$ & 3.9 \\
Citric acid & $0.957 \pm 0.073$ & 3.0 \\
Ethanol & $1.002 \pm 0.03$ & 1.3 \\
Acetic acid & $0.939 \pm 0.09$ & 3.7 \\
\hline
\end{tabular}

\section{Acknowledgements}

We greatly appreciate the support of the National Natural Science Foundation of China under the Key Program (20635020), Creative Research Group (20521503), and General Program (90606016). This work is also supported by National Basic Research Program of China (2006CB933201) and the European Community Sixth Framework Program through a STREP Grant to the SELECTNANO Consortium, Contract No. 516922.

\section{References}

[1] Rusling, J. F.; Nassar, A. E. F. Enhanced electron-transfer for myglobin in surfactant films on electrodes. J. Am. Chem. Soc. 1993, 115, 11891-11897.

[2] Nassar, A. E. F.; Bobbitt, J. M.; Stuart, J. D.; Rusling, J. F. Catalytic reduction of organohalide pollutants by myoglobin in a biomembrane-like surfactant film. J. Am. Chem. Soc. 1995, 117, 10986-10993.

[3] Zhao, G. C.; Zhang, L.; Wei, X. W.; Yang, Z. S. Myoglobin on multi-walled carbon nanotubes modified electrode: Direct electrochemistry and electrocatalysis. Electrochem. Commun. 2003, 5, 825-829.

[4] Cai, C. X.; Chen, J. Direct electron transfer and bioelectrocatalysis of hemoglobin at a carbon nanotube electrode. Anal. Biochem. 2004, 325, 285-292.

[5] Zhou, H. H.; Chen, H.; Luo, S. L.; Chen, J. H.; Wei, W. Z.; Kuang, Y. F. Glucose biosensor based on platinum microparticles dispersed in nano-fibrous polyaniline. Biosens. Bioelectron. 2005, 20, 1305-1311.

[6] Zhang, L.; Jiang, X.; Niu, L.; Dong, S. J. Syntheses of fully sulfonated polyaniline nano-networks and its application to the direct electrochemistry of cytochrome c. Biosens.
Bioelectron. 2006, 21, 1107-1115.

[7] Zhang, L.; Zhang, Q.; Li, J. H. Direct electrochemistry and electrocatalysis of hemoglobin immobilized in bimodal mesoporous silica and chitosan inorganicorganic hybrid film. Electrochem. Commun. 2007, 9, 1530-1535.

[8] Liu, X. Q.; Shi, L. H.; Niu, W. X.; Li, H. J.; Xu, G. B. Amperometric glucose biosensor based on single-walled carbon nanohorns. Biosens. Bioelectron. 2008, 23, 1887 -1890 .

[9] Sotiropoulou, S.; Chaniotakis, N. A. Carbon nanotube array-based biosensor. Anal. Bioanal. Chem. 2003, 375, 103-105.

[10] Banks, C. E.; Compton, R. G. Exploring the electrocatalytic sites of carbon nanotubes for NADH detection: An edge plane pyrolytic graphite electrode study. Analyst 2005, 130, 1232-1239.

[11] Wang, J. Stripping analysis at bismuth electrodes: A review. Electroanalysis 2005, 17, 1341-1346.

[12] Vamvakaki, V.; Tsagaraki, K.; Chaniotakis, N. Carbon nanofiber-based glucose biosensor. Anal. Chem. 2006, 78, 5538-5542.

[13] Lu, X. B.; Zhou, J. H.; Lu, W.; Liu, Q.; Li, J. H. Carbon nanofiber-based composites for the construction of mediator free biosensors. Biosens. Bioelectron. 2008, 23, 1236-1243.

[14] Sun, X. M.; Li, Y. D. Colloidal carbon spheres and their core/shell structures with noble-metal nanoparticles. Angew. Chem. 2004, 116, 607-611.

[15] Balasubramanian, K.; Burghard, M. Electrochemically functionalized carbon nanotubes for device applications. Small 2005, 1, 180-192.

[16] Cui, R. J.; Liu, C.; Shen, J. M.; Gao, D.; Zhu, J. J.; Chen, H. Y. Gold nanoparticle-colloidal carbon nanosphere hybrid material: Preparation, characterization, and application 
for an amplified electrochemical immunoassay. Adv. Funct. Mater. 2008, 18, 2197-2204.

[17] Stargardt, J. F.; Hawkridge, F. M.; Landrum, H. L. Reversible heterogenous reduction and oxidation of sperm whale myoglobin at a surface modified gold minigrid electrode. Anal. Chem. 1978, 50, 930932.

[18] Hildebrand, D. P.; Tang, H. L.; Luo, Y. G.; Hunter, C. L.; Smith, M.; Brayer, G. D.; Mauk, A. G. Efficient coupled oxidation of heme by an active site variant of horse heart myoglobin. J. Am. Chem. Soc. 1996, 118, 1290912915.

[19] Yabuki, S.; Shinohara, H.; Aizawa, M. Electro-conductive enzyme membrane. J. Chem. Soc. Chem. Commun. 1989, 945-946.

[20] Laviron, E. General expression of the linear potential sweep voltammogram in the case of diffusionless electrochemical systems. J. Electroanal. Chem. 1979, 101, 19-28.

[21] Kendrew, J. C.; Bodo, G.; Dintzis, H. M.; Parrish, R. G.; Wyckoff, H.; Phillips, D. C. A three-dimensional model of the myoglobin molecule obtained by X-ray analysis. Nature 1958, 181, 622-666.

[22] Leitch, F. A.; Moore, G. R.; Pettigrew, G. W. Structural basis for the variation of $\mathrm{pH}$-dependent redox potentials of Pseudomonas cytochromes C-551. Biochem. 1984, 23, 1831-1838.

[23] Wyman, J. Regulation in macromolecules, as illustrated by hemoglobin. Quart. Rev. Biophys. 1968, 35-80.

[24] Bond, A. M. Modern Polarographic Methods in Analytical Chemistry. M. Dekker: New York, 1980, pp. 27-45.

[25] Yamazaki, I.; Araiso, T.; Hayashi, Y.; Yamada, H.; Makino, R. Analysis of acid-base properties of peroxidase and myoglobin. Adv. Biophys. 1978, 11, 249-281.

[26] Tatsuma, T.; Mori, H.; Fujishima, A. Electron transfer from diamond electrodes to heme peptide and peroxidase. Anal. Chem. 2000, 72, 2919-2924.

[27] Kamin, R. A.; Wilson, G. S. Rotating-ring-disk enzyme electrode for biocatalysis kinetic-studies and characterization of the immobilized enzyme layer. Anal. Chem. 1980, 52, 1198-1205.

[28] Zhao, Y. D.; Bi, Y. H.; Zhang, W. D.; Luo, Q. M. The interface behavior of hemoglobin at carbon nanotube and the detection for $\mathrm{H}_{2} \mathrm{O}_{2}$. Talanta 2005, 65, 489494.

[29] Zhao, X. J.; Mai, Z. B.; Kang, X. H.; Dai, Z.; Zou, X.Y. Clay-chitosan-gold nanoparticle nanohybrid: Preparation and application for assembly and direct electrochemistry of myoglobin. Electrochim. Acta 2008, 53, 4732-4739.

[30] Zong, S. Z.; Cao, Y.; Zhou, Y. M.; Ju, H. X. Reagentless biosensor for hydrogen peroxide based on immobilization of protein in zirconia nanoparticles enhanced grafted collagen matrix. Biosens. Bioelectron. 2007, 22, 17761782. 